\title{
Strategies to Support Facility Management Resourcing Building Information Modelling
}

\author{
Raquel V. Matos ${ }^{1}$, Fernanda S. Rodrigues ${ }^{2}$, Hugo F. Rodrigues ${ }^{3}$ and Aníbal G. Costa \\ ${ }^{1}$ RISCO, Civil Engineering Department, University of Aveiro, Campus Universitário de Santiago, \\ 3810-193 Aveiro, Portugal, rvpm@ua.pt. \\ 2 RISCO, Civil Engineering Department, University of Aveiro, Campus Universitário de Santiago, \\ 3810-193 Aveiro, Portugal,mfrodrigues@ua.pt. \\ ${ }^{3}$ RISCO, Civil Engineering Department, University of Aveiro, Campus Universitário de Santiago, \\ 3810-193 Aveiro, Portugal, hrodrigues@ua.pt. \\ ${ }^{4}$ RISCO, Civil Engineering Department, University of Aveiro, Campus Universitário de Santiago, \\ 3810-193 Aveiro, Portugal, agc@ua.pt.
}

\begin{abstract}
The significant growth of the building stock in the 20th century allied to the low rate of building retrofitting over the last years results in the current low conservation level of the Portuguese building stock. The building natural aging, associated with the lack of planned maintenance actions and the climate changes consequences contributed to accelerating the degradation of building materials in the existing buildings, leading to a poor conservation of Portuguese public building stock. So, to extend the service life of the materials, the application of appropriate maintenance actions is imperative. This work aims to assess the building performance and to prioritize the maintenance actions employing Key Performance Indicators using Building Information Modelling (BIM) as a supporting tool for building condition assessment and maintenance management. To achieve these goals the following methodology was applied to a case study: 1)Building Information Collection; 2) Building Life Cycle Cost Estimation, and 3) Automated calculation of Building Performance Indicator supported by BIM, using Revit software and Dynamo programming. The application of this maintenance management automated strategy shows the importance of BIM in Facility Management; permits the model's permanent update of information decreasing the probability of information loss and the consequent investment in data collection, and has high potential to prioritise the building maintenance actions, extending the materials service life and building durability.
\end{abstract}

Keywords: Building Condition Assessment (BCA), Key Performance Indicators (KPIs), Building Service Life, Durability, Dynamo, Building Information Modelling (BIM).

\section{Introduction}

To slow down the buildings' degradation processes and consequently the increase of the materials lifetime is essential to implement suitable, cost-benefit maintenance actions through cost and time effective maintenance management systems. A consistent building performance evaluation taking advantages of quantifiable tools to evaluate Building Condition Assessment (BCA) is crucial to meet an efficient and sustainable maintenance strategy in the scope of the Facility Management (FM) (Abbot et al., 2007; Marmo et al., 2019).Therefore, the main objective of this work is to assess the building performance by the integration of KPIs in a BIM software - the Autodesk Revit - and through this software to prioritize the maintenance actions in a practical and automated way. These KPIs were applied to the building of the Civil 
Engineering Department of the University of Aveiro to support FM systems and maintenance planning. For this purpose, the research pursued a methodology with the following steps: 1) Building information collection; 2) Building Life Cycle Cost estimation; 3) Automated calculation of BPI supported by BIM, using Revit software and Dynamo programming. This study contributes to optimize the maintenance management of the Aveiro's University campus and to provide an easy instrument to prioritize maintenance, based on existing and reliable performance metrics and leveraging new technologies like BIM. In the next sections, some important concepts are approached to understand the methodology applied that is presented and validated by applying them to a case study. In the end the results are presented and discussed.

\section{Conceptual Review}

According to Crawford (2011) and Ngwepe et al. (2015) there are six building life cycle stages, consuming the last three stages, namely the construction, operation and demolition, approximately $15 \%$ of world's freshwater resources, $36 \%$ of the world's energy; and produce about $40 \%$ of the world's greenhouse gas emissions (Ngwepe, 2015; Maslesa et al., 2018; IEA, 2020). As almost all the buildings have a lifespan of over 50 years the operation stage is the longest, during which the performance of buildings relies on the proper operation and maintenance (O\&M) (Lai et al., 2007). For this purpose, the continuous monitoring at regular intervals is needed to identify indicators that precede failures and to perform necessary maintenance work at the right time. So, the so-called predictive maintenance starts with the

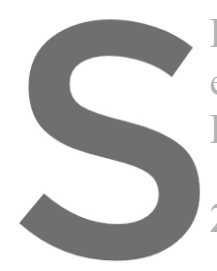
$\mathrm{BCA}$, which can be monitored by parameters that indicate early signs of failure leading to the beginning of maintena Bortolini; et al., 2016)

2.1 Building Condition Assessment

Building Condition Assessment (BCA) should be the basis for management and maintenance

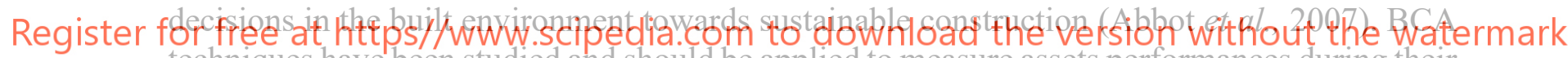
techniques have been studied and should be applied to measure assets performances during their service life, to consequently maintain them most effectively (CEN/ TS 17385:2019; Dejaco et al., 2017; Wahida et al., 2012). According to Dejaco et al. (2017) and Marmo et al. (2019) to a BCA successfully oriented, the KPIs are the best way to measure the buildings' performance allowing to have accessible and useful information about buildings and their parts.

\subsection{Key Performance Indicators (KPIs)}

KPIs system aims to provide a measure of current performance and a clear statement of performance targets, as well as an evaluation of performance progress (Maslesa et al., 2018).

Building owners claim KPIs, mainly to understand the conditions of their assets and consequently, to allocate a suitable budget for maintenance or refurbishment and support their maintenance choices. Accordingly, the importance of measuring building performance through KPIs have been emphasized (Marmo et al., 2019). Nevertheless, these methodologies mostly tend to evaluate the performance of the whole building and not the single components, mainly using analyses of users' satisfaction. For this reason, a Building Performance Indicator (BPI) was chosen for this study application, since it evaluates the performance of buildings and its systems. 


\subsubsection{Building Performance Indicator}

The Building Performance Indicator (BPI) was developed by Shohet (a) et al. (2003); Shohet (c) (2003) Shohet (2006). A value between 0 and 100 defines this indicator, that expresses the building's state, by the performance evaluation of its various systems (Pn). The BPI is obtained by equation 1 .

$$
\mathrm{BPI}=\sum_{n} P_{n} \times W_{n}
$$

Where:

BPI - Building Performance Indicator (on a scale of 0-100):

$\mathrm{Pn}$ - Performance level for system $\mathrm{n}$ (on a scale of 0 to 100) as determined by equation 2 .

Wn - Weight of each building system n, as determined by Life Cycle Costs (LCC).

The BPI value indicates the performance level of the building studied, according to the followed categories: BPI $>80$ indicates that the use of the building, and its subsequent performance, are good or better; $70<\mathrm{BPI}<80$ indicates that the state of the building is such that some of the systems are in marginal condition; $60<\mathrm{BPI} \leq 70$ reflects the deterioration of the building; BPI $<60$ means that the building is run-down.

Each building's system is evaluated according to three criteria: actual physical performance of the systems (Cn); frequency of failures in building systems (Fn); and actual preventive maintenance carried out on the systems (PMn) and their correspondent weights $W(C)_{n}, W(F)_{n}$ and $W(\mathrm{pm})_{\mathrm{n}}$. The combination of these three elements represents the performance level of the

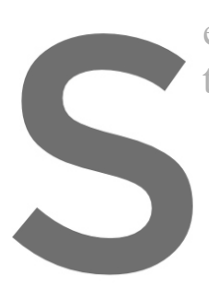
entire system (Pn) (Equation 2). This indicator

the LCC.
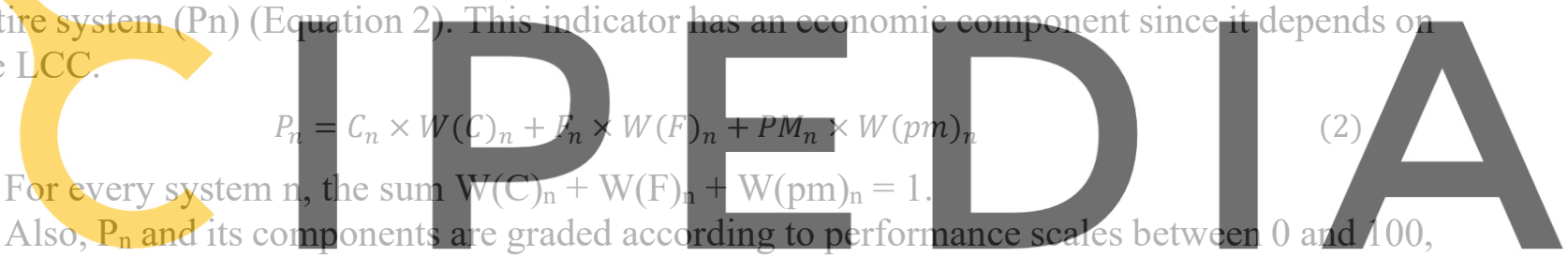

like BPI. The weighting of each building system (Wn) is accomplished by weighting the

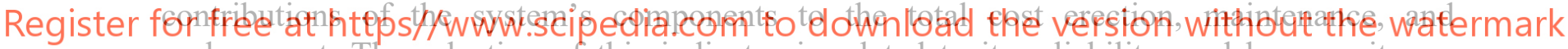
replacement. The selection of this indicator is related to its reliability, and because it was previously validated by 6 experienced facility managers in maintenance (Lavy \& Shohet, 2004).

\subsection{KPIs integration within Building Information Modelling}

According to ISO 29481-1(2014) BIM is a shared digital representation of the physical and functional characteristics of any built object, to facilitate design, construction and operation processes to form a reliable decision basis. In FM, BIM includes unified information base, consisting in a Big Data database, providing a building owner's manual, useful support for analysis, support for emergency response, security management and scenario planning (IFMA, 2013; Rodrigues et al., 2019). Revit is a BIM software offering a multi-disciplinary and collaborative approach to the design and construction process. To add extra functionalities to import/export data parameters from Revit to Excel, Dynamo tool can be used, as an add-in for extending Revit's parametric functionality and information retrieval (Autodesk Dynamo, 2020; Sadeghi et al., 2019). Aboumoemen et al. (2017) verified that the linkage between BIM and KPIs to measure the building performance is an untimely task. So, in the present study, the potential of the linkage between BIM and KPIs to demonstrate the agility of the FM strategy researched is explored and verified. 


\section{Case Study}

After the theoretical approach, the automated building performance indicator calculation and its extraction were applied to the Civil Engineering Department of Aveiro's University, built in 2004/2005, located in Aveiro, mainland Portugal.The methodology applied is described in the following points.

\subsection{Building Information Collection}

The Civil Department of Aveiro's University aims to provide an educational environment for its students and professors. With a plan area of $1613 \mathrm{~m} 2$, it is a building with four floors, one below the ground floor and three above the ground level, including the ground floor. Its main facade has a northeast orientation. Figure 1 is a plan of Aveiro's University Campus of Santiago representing in yellow the case study building location. The structural foundations are in reinforced concrete piles. The major part of the structure (columns and beams) are metallic, and the slabs are in reinforced concrete. The roof structure consists of steel columns and beams and tubular sections that support the metallic tile. The rainwater drainage system is characterized by galvanized zinc gutters and the dropp tubes in PVC-U. In terms of building interior finishing, the floors are in vinyl coating in the classrooms, and in the professors' offices the floor coating is in cork mosaic. The ceilings are mainly covered with plasterboard painted and in exposed concrete. The exterior doors and windows are in metallic profiles. In Figure 2, it is possible to observe a 3D model of the civil engineering department developed in Revit by Tavares (2019)
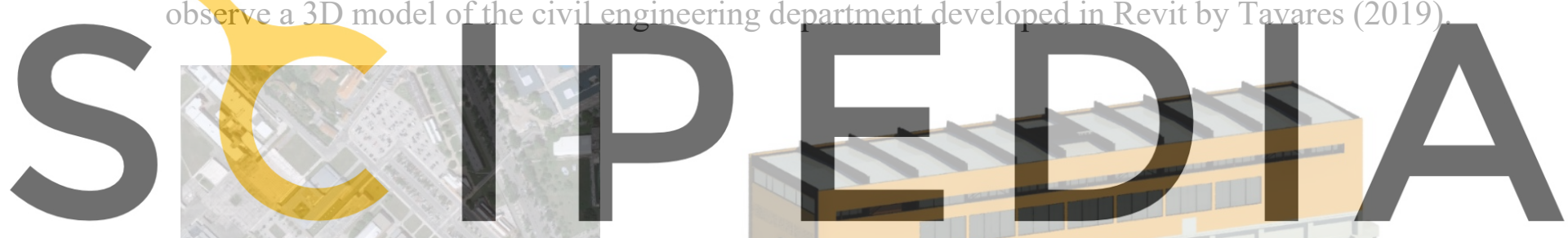

Register for free at https//www.scipedia.com
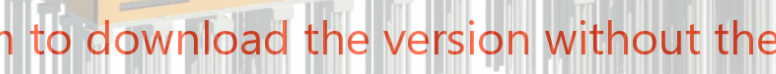

watermark

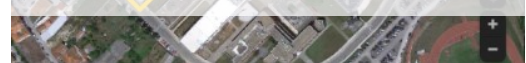

Figure 1. Building location in Aveiro's University Santiago Campus.
Figure 2. Revit model of the Civil Engineering Department of Aveiro's University (Tavares, 2019).

To understand the current periodicity of maintenance actions and to identify the main building anomalies, interviews with employees, lecturers and pivots in charge of management and maintenance of the building were carried out. The building plans, elevations, costs estimation and maintenance records were requested. Afterwards, a building inspection was accomplished and a report related to the assessment of buildings' deterioration state was done. Then, a set of building systems was selected to be evaluated by Pn's criteria such as windows, roofs, structural framing, structural columns, interior and exterior walls, mechanical and safety equipment, doors, drainage system, electric system, and lifts.

\subsection{Building Life Cycle Cost Estimation}

The economic contribution of each building system (Wn) selected to include in the BPI was 
calculated by life cycle cost estimation. The contribution of each building system was given in percentage for the three alternative scales to include in BPI calculation: 1) Construction costs, 2) Maintenance Costs index, 3) Life Cycle Cost index. Despite being an essential step of this study, the results obtained in this step are not herein presented since it is out of this paper focus.

\subsection{Automated Evaluation of BPI Supported by BIM}

In this step, the integration of BPI into the Revit software with shared parameters and resourcing Dynamo to extract them as a final value to Microsoft Excel took place. In Revit software, the shared parameters are parameters attributed to the different object families with several types of information, which in this case allows associating the $\mathrm{Cn}, \mathrm{Fn}, \mathrm{PMn}, \mathrm{Wn}(\mathrm{Cn}), \mathrm{Wn}(\mathrm{Fn})$ and $\mathrm{Wn}(\mathrm{Pmn})$ criteria and its contribution to each family objects. After the parameters attribution and based on the building inspection and the LCC calculated in the previous step of this methodology, it is possible to attribute to each system a quantifiable evaluation and contribution as depicted in the Revit schedule, automatically extracted, in Figure 3.

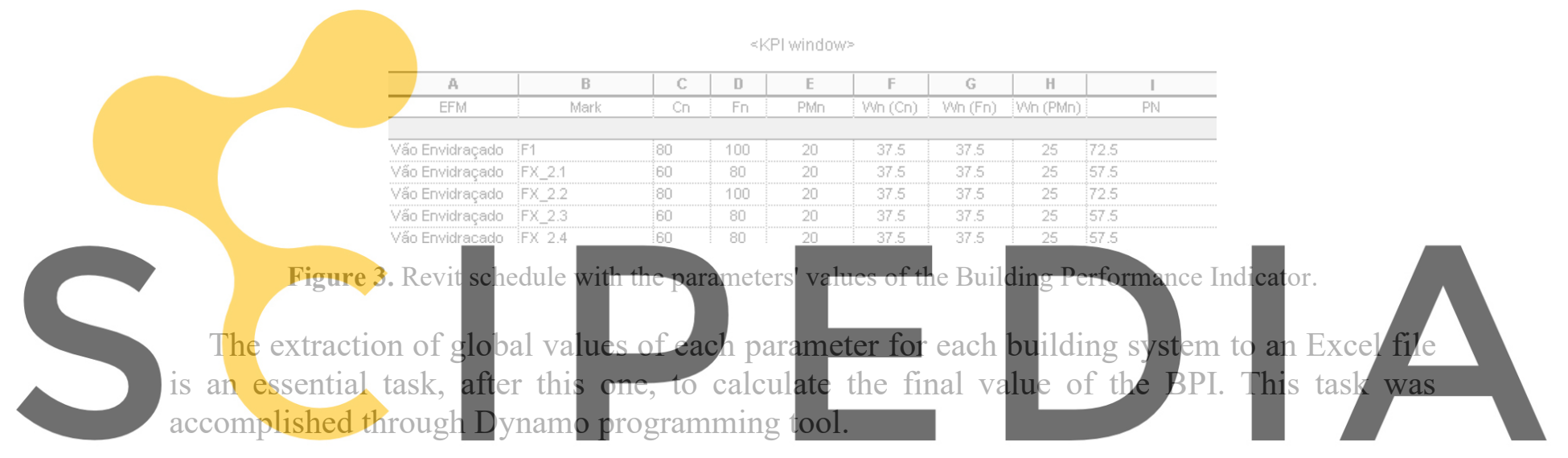

Register forfree at thittps/fwww.scipedia.compto download the version without the watermark

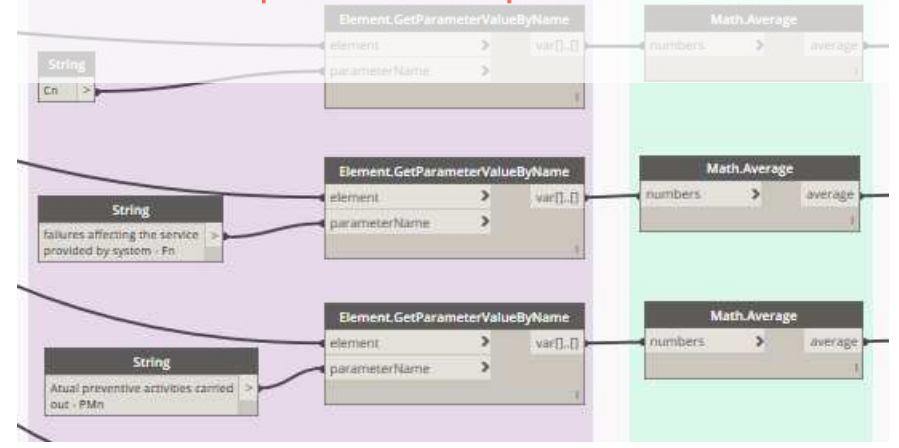

a)

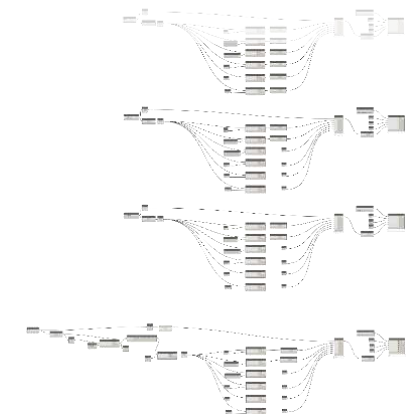

b)

Figure 4 - a) Selection of parameters to be extracted and the calculation of the global value of each one. b) Piece of work from visual programming in Dynamo BIM to extract parameters from every category.

The interaction between the three software pretends to take advantage of its interoperability (Revit-Dynamo and Excel), to create an automated method that allows prioritizing maintenance actions. Thus, the Dynamo BIM allows selecting the category of elements and the parameters which is pretended to extract, generating the global value of each parameter correspondent to 
each category of elements. Figure 4 shows part of the visual programming developed on the interface of Dynamo BIM software.

Then, the contribution of each element calculated for the total LCC in step 2 was included in the Excel sheet. After this, the BPI was calculated as presented in Figure 5.

\begin{tabular}{|l|c|c|c|c|c|c|c|c|c|}
\hline Element & Cn & Fn & PMn & W(Cn) & W(Fn) & W(PMn) & Pn & Wn & BPI \\
Windows & 73.78 & 79.49 & 21.54 & 37.50 & 37.50 & 25.00 & 62.86 & 7.86 & 4.94 \\
Roofs & 40.00 & 60.00 & 40.00 & 37.50 & 37.50 & 25.00 & 47.50 & 8.96 & 4.26 \\
Structural Framing & 78.39 & 100.00 & 20.00 & 45.00 & 45.00 & 10.00 & 82.28 & 9.85 & 8.10 \\
Structural Columns & 78.72 & 98.72 & 20.00 & 45.00 & 45.00 & 10.00 & 81.85 & 9.85 & 8.06 \\
Walls Exterior & 80.00 & 80.00 & 20.00 & 37.50 & 37.50 & 25.00 & 65.00 & 7.86 & 5.11 \\
Walls Interior & 80.00 & 80.00 & 20.00 & 35.00 & 35.00 & 30.00 & 62.00 & 17.49 & 10.84 \\
Mechanical Equipment & 20.00 & 20.00 & 20.00 & 20.00 & 20.00 & 50.00 & 18.00 & 2.45 & 0.44 \\
Doors & 79.62 & 80.00 & 40.19 & 35.00 & 35.00 & 30.00 & 67.92 & 17.49 & 11.88 \\
Drainage system & 80.00 & 80.00 & 50.00 & 37.50 & 37.50 & 25.00 & 72.50 & 3.18 & 2.31 \\
Electric system & 100.00 & 90.00 & 50.00 & 25.00 & 25.00 & 50.00 & 72.50 & 5.25 & 3.80 \\
Elevators & 100.00 & 100.00 & 80.00 & 30.00 & 30.00 & 40.00 & 92.00 & 8.28 & 7.62 \\
Security (Fire, CTV) & 100.00 & 100.00 & 60.00 & 37.50 & 37.50 & 25.00 & 90.00 & 1.49 & 1.34 \\
\hline
\end{tabular}

Figure 5. Excel file with parameters and categories exported from Revit software by Dynamo software and BPI calculation.

\subsection{Results Analysis}

The value of the BPI obtained indicates the deterioration level of the building, meaning that preventive and break-down maintenance activities must be carried out since the value obtained is between $60<\mathrm{BPI} \leq 70$, according to the anomalies detection during the building inspection.

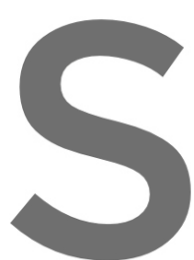
Besides being a globait

priorities of the mainte establish the interventi observe that the HVAC that is the one that needs in the second place by the

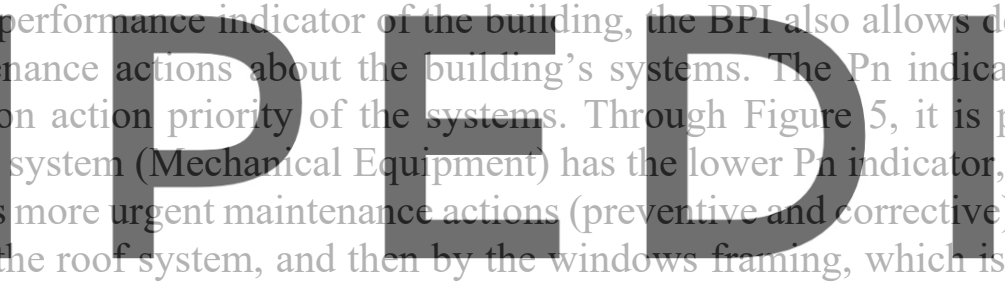
defining the
cator should
or, indicating
is ), folloyed
is according to the building inspection done.

Register for free at https//www.scipedia.com to download the version without the watermark 3.5 Application of "Collor Splasher" to BIMI Model

To simplify the maintenance management process, the values obtained in Figure 5 were categorized by colours, resourcing the color splasher BIM plug-in, which allows a quick recognition about building condition systems as it is presented in Figure 6.

The colour categorization to express the actual system's condition was done, in which red colour indicates urgency in system intervention and green colour indicates the satisfactory condition of the system. 


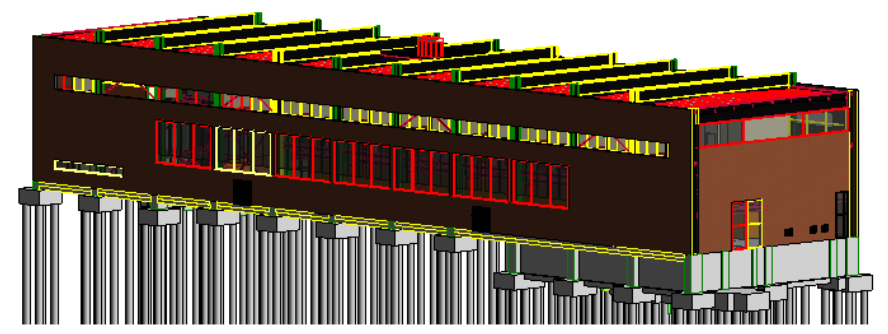

Figure 6. "Color splasher" application to 3D View of the building model.

With Figure 6, it is possible to observe easily and quickly that HVAC system, roof system, and windows framing are the ones that more urgently need maintenance actions, as mentioned above.

\section{Final Conclusions}

The methodology developed is innovative because it allows collecting and analyse the diversified information about building systems condition, permits calculating the systems' and the whole building's performance in an automated way. This calculation is possible through shared parameters attributing the BPI parameters to Revit object families, and through interoperability Revit-Dynamo-Excel. Besides that, to facilitate the process of setting priorities of maintenance

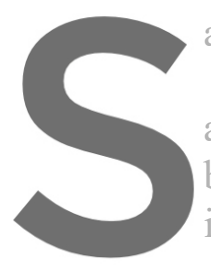
actions, the maintenance

This methodology application allows pr building information shar its application leads to the easier ce priorities were categor
an be applied to any buil
he easitizing the maintenance rized by colour
ding typology
e actions in ex
lding anomalie
cle information in the BIM model.
and it is very releva
xisting buildings,
record and analys
retrieval, contribut

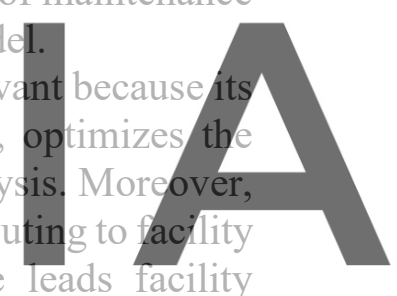
managers time and money-saving. The evaluation of systems performance leads facility managers in identifying anomalies early enough to minimize the impact of operational
Register fortref af. by using BIM was proved, and it motivates the FM implementation, which contributes to increasing the materials service life.

As a future study is proposed the development of an assessment approach, based on a set of KPIs, for measuring environmental building performance and green maintainability.

\section{Acknowledgemnts}

This research work was funded by the Portuguese Government through the FCT under the $\mathrm{PhD}$ grant SFRH/BD/147532/2019, awarded to the first author.

\section{ORCID}

Raquel V. Matos: https://orcid.org/0000-0002-0171-7842?lang=pt

Fernanda S. Rodrigues: https://orcid.org/0000-0001-9127-7766

Hugo F. Rodrigues: https://orcid.org/0000-0003-1373-4540

Aníbal G. Costa: https://orcid.org/0000-0001-8950-4843

\section{References}

Abbot, G. R. McDuling, J. J. Parsons, S. and Schoeman J.C. (2007). Building condition assessment: A 
performance evaluation tool towards sustainable asset management. CIB World Building Congress 2007. pp. 649-662: Construction for Development, Cape Town, South Africa, 14-17 May.

Aboumoemen, A. and Underwood, J. (2017). A Bim Maturity-KPI Assessment : Literature Review. 13th International Postgraduate Conference, September 2017, University of Salford, Salford, UK.

Autodesk Dynamo. (2020). What is Dynamo?. Available in https://primer.dynamobim.org/01_Introduction/12_what_is_dynamo.html

Bortolini, N. Forcada, M. and Macarulla, M. (2016). BIM for the integration of building maintenance management - a case study of a university campus. In $C$. \& Scherer (Ed.), eWork and eBusiness in Architecture, Engineering and Construction. Taylor \& Francis Group. ISBN 978-1-138-03280-4.

Crawford, R. (2011). Life Cycle Assessment in the Built Environment. In Book. In Spon Press (Ed.), Society. Taylor \& Francis.

CEN / TS 17385. (2019). CEN TS 17385: Method for Condition Assessment od Immobile Constructed Assets. https://doi.org/ISBN:9780580519024.

Dejaco, M. C. Re Cecconi, F. and Maltese, S. (2017). Key Performance Indicators for Building Condition Assessment. Journal of Building Engineering, 9, 17-28. https://doi.org/10.1016/j.jobe.2016.11.004.

IEA. (2020). International Energy Agency - Buildings - A source of enormous untapped efficiency potential. Available in https://www.iea.org/.

IFMA. (2013). BIM for Facility Managers. In Book. P. Teicholz (Ed.), John Wiley \& Sons, Inc., Hoboken, New Jersey. ISBN: 978-1-118-38281-3

ISO 29481-1. (2014). International Organization for Standardization - ISO 29481-1:2014 - Building Information Models - Information delivery Manual - Part1: Methodology and format.

Lai, J. H. K. and Yik, F. W. H. (2007). Monitoring building operation and maintenance contracts. Facilities, 25(56), 238-251. https://doi.org/10.1108/02632770710742200.

Lavy, S. and Shohet, I. M. (2004). Integrated maintenance management of hospital buildings: A case study. Construction Management and Economics, 22(1), pp.25-34 Model to Support Fa

Maslesa, E. Jensen, P. A. and A systematic literature https://doi.org/10.1016/j.jobe.2018.06.006.

Ngwepe, L. (2015). A theort
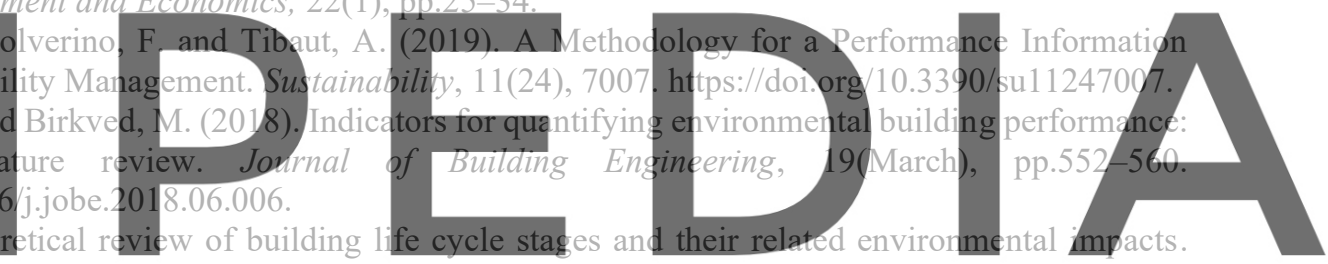

Available at: https://core.ac.uk/download/pdf/54198925.pdf

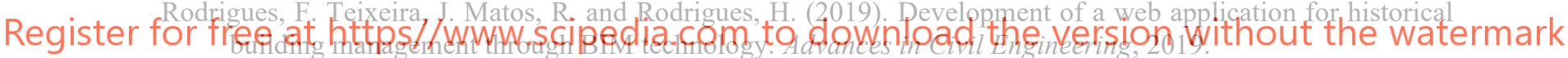

Sadeghi, M. Elliott, J. W. Porro, N. and Strong, K. (2019). Developing building information models (BIM) for building handover, operation and maintenance. Journal of Facilities Management, 17(3), 301-316. https://doi.org/10.1108/JFM-04-2018-0029.

Selcuk, S. (2017). Predictive maintenance, its implementation and latest trends. Proceedings of the Institution of Mechanical Engineers, Part B: Journal of Engineering Manufacture, 231(9), pp.1670-1679. https://doi.org/10.1177/0954405415601640.

Shohet (a), I. M. Lavy-Leibovich, S. and Bar-On, D. (2003). Integrated maintenance monitoring of hospital buildings. Construction Management and Economics, Vol. 21(2), pp.219-228.

Shohet (b), I. M. (2003). Key performance indicators for maintenance of health-care facilities. Facilities, Vol.21, pp. 5-12. https://doi.org/10.1108/02632770310460496.

Shohet (c), I. M. (2003). Building evaluation methodology for setting maintenance priorities in hospital buildings. Construction Management and Economics, Vol.21(7), pp.681-692. https://doi.org/10.1080/0144619032000115562.

Shohet, I. M. (2006). Key performance indicators for maintenance of healthcare facilities. Journal of Construction Engineering and Management, Vol. 21(April), pp.5-12.

Tavares, E. (2019). Gestão do Património Edificado com Recurso ao BIM, (In Portugueses), Master Thesis, Universidade de Aveiro, Aveiro, Portugal.

Wahida, R. N. Milton, G. Hamadan, N. Lah, N. M. I. B. N. and Mohammed, A. H. (2012). Building Condition Assessment Imperative and Process. Procedia - Social and Behavioral Sciences, Vol. 65(November 2015), pp.775-780. https://doi.org/10.1016/j.sbspro.2012.11.198. 